\title{
Physical and 3D Numerical Simulations of the Flow in the Tailrace of a Hydroelectric Power Plant to Design Fishway Entries
}

\author{
Agnès Leroy, Pierre Bourqui, Lionel Dumond \\ and Giovanni De Cesare
}

\section{Introduction}

The design of fishway entries has traditionally been done through the use of physical models. To our knowledge, the use of numerical models is still rare for such problems, even though the numerical simulation of the flows inside the fishways has been presented by various authors (see [1-3] for example). This is due to the complexity of the interaction between the flow in the tailrace and the flow coming from the fishway entry. To simulate such flows, the numerical model should be able to represent a highly turbulent free-surface flow in 3D. With the improvement of the numerical tools for Computational Fluid Dynamics, such simulations now seem feasible (see [4]). This work aims at modelling the flow in the tailrace and afterbay of the Rhinau Power plant (France) in order to design fishway entries. A physical model and a 3D numerical model were built and are complimentary for the design. Here, we focus only on the modelling of the current configuration of the power plant (without fishway entries), for which field measurements and observations are available. The aim is to qualify them for the design

\footnotetext{
A. Leroy $(\bowtie)$

EDF R\&D, LNHE, 5 quai Watier, 78400 Chatou, France

e-mail: agnes.leroy@edf.fr

P. Bourqui · G. De Cesare

EPFL Lausanne, LCH, Station 18, 1015 Lausanne, Switzerland

e-mail: pierre.bourqui@epfl.ch

G. De Cesare

e-mail: giovanni.decesare@epfl.ch

L. Dumond

EDF CIH, 4 rue Claude Marie Perroud, 31096 Toulouse Cedex, France

e-mail: lionel.dumond@edf.fr
} 
of the fishway entries. This paper is organized into two main parts: the description of the two models, followed by the results and comparisons with field measurements.

\section{Physical and Numerical Models}

For both models, the entire channel has to be represented since it does not present any symmetry. Even when all the turbines work at the same power, the observed flow on site in the tailrace presents a left-hand deviation. Besides, when one turbine is stopped, large circular flow patterns develop in the tailrace. In order to represent them, the model should span at least $200 \mathrm{~m}$ downstream of the power plant. On the other hand, some ADCP measurements are available at the exit of the afterbays but only for specific exploitation configurations. In order to build models able to simulate any exploitation configuration, the influence of the flow in the afterbays has to be simulated. This is why the models include the afterbays, from below the turbine to the tailrace. The bypass channel was also represented in the models, even though we never consider it in use for the fishway entries design. The model's real size is thus of about $280 \mathrm{~m}$. The tailrace is $167 \mathrm{~m}$ wide and the power plant is $127 \mathrm{~m}$ wide.

\subsection{Physical Model}

\subsubsection{Overview}

The physical model has been built in accordance with the original civil plans and actual latest laser measurements. The chosen geometric scale is $1 / 35$, big enough to reproduce the flow turbulence in the afterbay and in the tailrace while respecting the space restriction in the laboratory. The model's dimensions are approximatively $5 \times 10 \mathrm{~m}$.

The main components of the model are (Fig. 1) as follows:

1. Water supply from the pumping system of the lab, with the monitoring of the total discharge.

2. Two reservoirs for the distribution of the total discharge towards the four groups, with individual discharge control through magnetic flowmeters.

3. Four turbine units, preceded by deflectors to give the flow the rotational speed observed at the turbine's outlet.

4. Fishway entries located on top of the afterbays' outlets. The discharge through those entries is controlled individually with rotameters. 


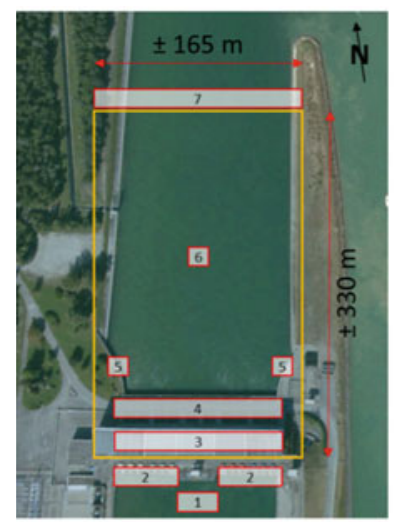

$\stackrel{100 \mathrm{~m}}{\longrightarrow} \square$ timites modele physique
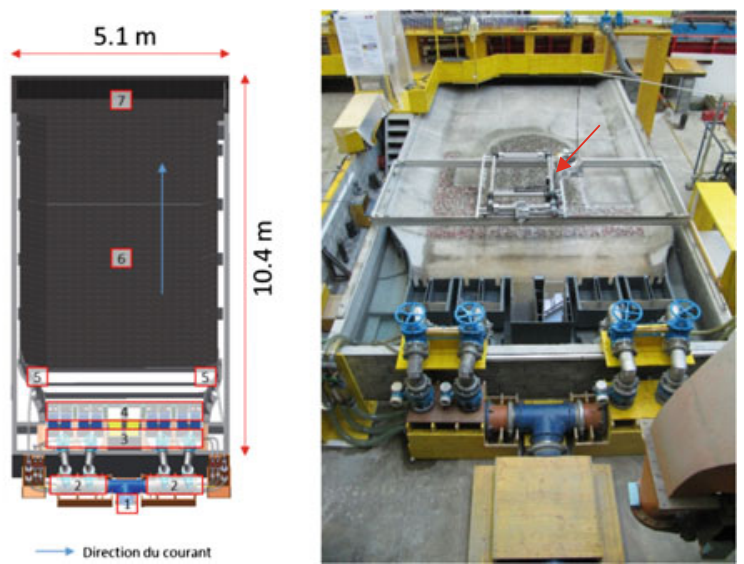

Fig. 1 Left and middle-main components and dimensions of the physical model. Rightphysical model in the laboratory (Satellite image: Google Earth)

5. Downstream connecting walls, at the end of which the bank fishway entries will be placed.

6. Tailrace.

7. Restitution basin with a weir that controls the water level in the tailrace.

\subsubsection{Conception}

The model has been first designed and assembled with the CAD software Autodesk Inventor. Two materials have been used for the manufacture of the different parts. The afterbays, the body of the power plant, the connecting walls and the fishways are made with PVC. The topography of the afterbay and the tailrace have been fixed with a $50 \mathrm{~mm}$ dick concrete layer. The level of precision for each component of the model depends on the material it is made of: $\pm 1 \mathrm{~mm}$ for the PVC parts and $\pm 5 \mathrm{~mm}$ for the concrete parts.

\subsubsection{Scale Effect}

The model is scaled in respect to the Froude similarity, meaning that the relation between the inertial and gravity forces is preserved. This admits the same Froude number for both the prototype and the model. The Reynolds number has been found bigger than $3.5 \times 10^{4}$ for all discharges, with the consequence that the turbulence level is high enough to limit the scale effects in the model [5]. 


\subsubsection{Measuring Devices and Accuracy}

To evaluate the flow in the model, velocities are measured in 3 directions with Ultrasound Velocity Profiler (UVP) of Met-Flow SA. The UVP represents both a method and a device for measuring an instantaneous velocity profile in liquid flow by detecting the Doppler shift frequency of echoed ultrasound as a function of time [6]. The accuracy of the velocity measurements with the UVP reaches $\pm 1 \mathrm{~mm} / \mathrm{s}$, corresponding to a potential error of less than $1 \%$ of the mean velocity in the tailrace.

The UVP transducers are placed on a robotic arm (pointed by the red arrow in Fig. 1, right) that allows to program automatic measurement sequences. The robot itself can be moved on a frame that spans the model and that can be rolled up and downstream. Thanks to this infrastructure, the measurement procedure is flexible and reproducible.

\subsubsection{Measurement Procedure}

Two types of information have been recorded on site: observations of the surface flow and ADCP (Acoustic Doppler Velocity Profiler) measurements of the subsurface. The same data have to be collected on the physical model. Therefore, two types of grids have been built, each with a mesh size of $100 \mathrm{~mm}$ (Fig. 2). The mesh size represents the distance between two robot positions. At each position, both UVP transducers record a velocity profile with a resolution of $5.2 \mathrm{~mm}$.
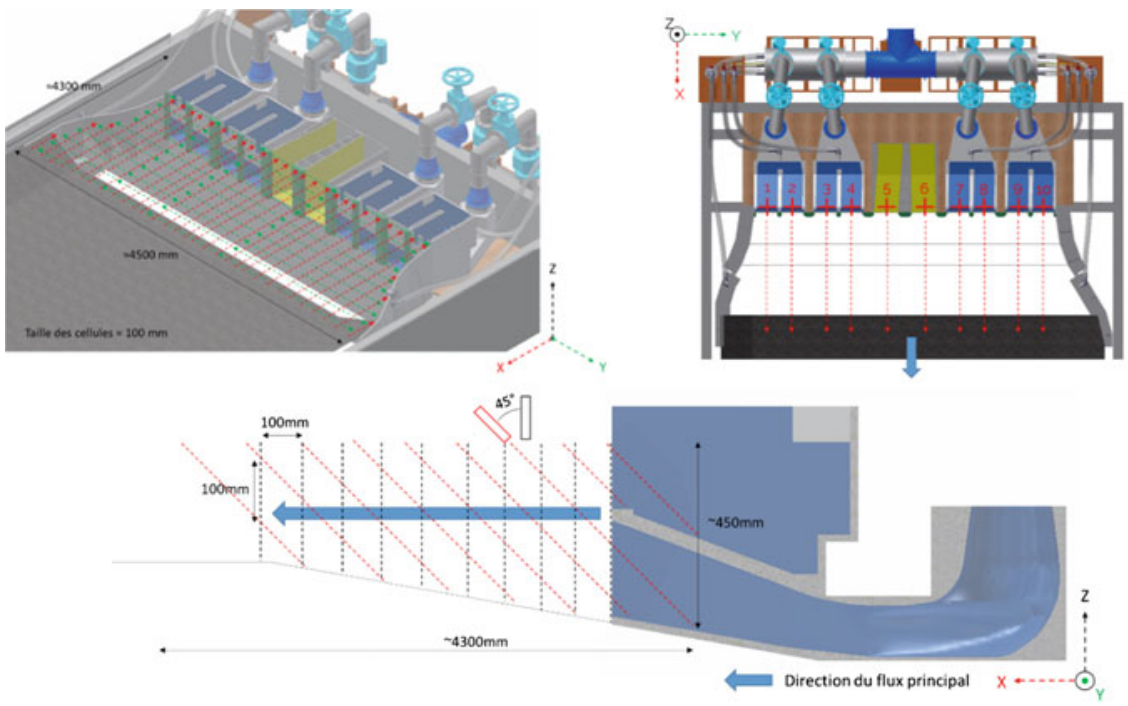

Fig. 2 Schematic representation of the flow measurement procedure. Top left: surface flow $(X-$ $Y$ plane). Top right and bottom: subsurface flow ( $X-Z$ planes) 
In total, 83'440 points are recorded for the surface flow of one single turbining configuration. It covers the whole width of the tailrace and the first $160 \mathrm{~m}$ downstream of the power plant. The $10 X-Z$ planes represent $68^{\prime} 568$ measured points, covering the whole depth and the first $160 \mathrm{~m}$ downstream of the power plant. Each point is characterized by its spatial coordinates $X, Y, Z$ and has a related velocity. At the end, the interpolation over the whole domain of the data of each transducer creates a velocity field.

\subsection{Numerical Model}

The 3D geometry and mesh were built using the open-source Salomé software (version 7.6.0), based on the plants provided by the operator. The Fig. 3 shows the 3D geometry seen from above and zooms on the afterbays and a bypass channel. Care was taken to accurately reproduce the details of the geometry, in particular for the afterbays, the piers, the walls and the bypass channel. The presence of cells where the flow is quieter above the afterbays is visible in the Fig. 3, right. The inflow boundaries of the model are located below each of the four turbines, at 149.30 NGF.

The mesh is constituted of $877^{\prime} 861$ hexaedric elements of variable size (varying from about $20 \mathrm{~cm}$ in the afterbays, to about $3 \mathrm{~m}$ in the tailrace). Figure 3 shows a zoom on the mesh of the two groups of the right bank. The discretization is finer in the afterbays than in the tailrace. On the other hand, at the outflow boundary, the mesh was extruded in order to avoid distorted elements close to the outflow that could cause numerical instabilities. The extrusion was done on $3 \mathrm{~m}$ with a step of $1 \mathrm{~m}$.

The open-source software Code_Saturne (version 4.1) was used for the simulations, which makes it possible to use advanced Reynolds-Averaged NaviedStokes (RANS) models for turbulence and unstructured meshes. The $k-\varepsilon$ turbulence model with linear production available in Code_Saturne was tested with a dynamic molecular viscosity equal to $10^{-6} \mathrm{~m}^{2} \mathrm{~s}^{-1}$ and a density equal to $1000 \mathrm{~kg} \mathrm{~m}^{-3}$. The wall roughness was set to $1 \mathrm{~mm}$ and the following law (1) was used for the wall velocity $[7,8]$ :
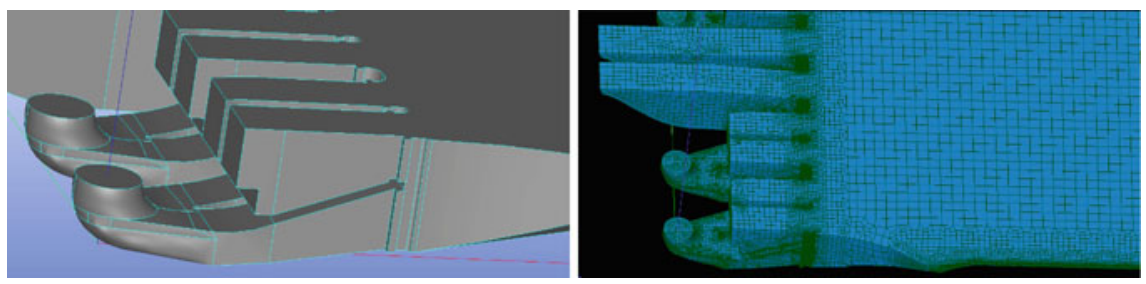

Fig. 3 3D representation of the geometry (left) and mesh (right) of the afterbays, bypass channel and tailrace: zoom on the two groups of the right bank (groups 3 and 4) 


$$
\bar{u}=\frac{u_{*}}{\kappa} \ln \frac{z / \zeta}{1 / 8.4 R e_{*}+1 / 33}
$$

where $\bar{u}$ is the mean wall velocity, $u_{*}$ the friction velocity (calculated by Code_Saturne), $\kappa$ the von Karman constant equal to $0.41, z$ the distance to the wall, $\zeta$ the roughness and $R e_{*}=\frac{\zeta u_{*}}{v}$ the friction Reynolds number. It makes possible to continuously switch between a smooth turbulent and a rough turbulent flow, which may happen in the afterbays and tailrace depending on the flowrates. There are four inflow boundaries, one below each turbine, where a uniform normal velocity is prescribed in agreement with the desired flowrate. The tangential velocities were prescribed based on the turbines characteristics and depend on the flowrate. Figure 4 shows the tangential velocities for three values of flowrate. The sign of the tangential velocity is positive for a clockwise rotation, negative otherwise. The turbulent quantities at the inflow boundaries are prescribed by Code_Saturne based on the hydraulic diameter $(8.45 \mathrm{~m})$ and a turbulent intensity. The values of 2, 10, 20 and $50 \%$ of turbulent intensity were tested, the latest providing the best results. Thus, only the results obtained with $50 \%$ of turbulent intensity at the inflows are presented here.

The downstream water level was set to $160.1 \mathrm{NGF}$, corresponding to a flowrate of $700 \mathrm{~m}^{3} / \mathrm{s}$. The standard outflow boundary condition of Code_Saturne was used, corresponding to a homogeneous Neumann boundary condition applied on all the convected variables [8]. Considering that the displacement of the free-surface is observed to be small in the tailrace, the free-surface was considered motionless in

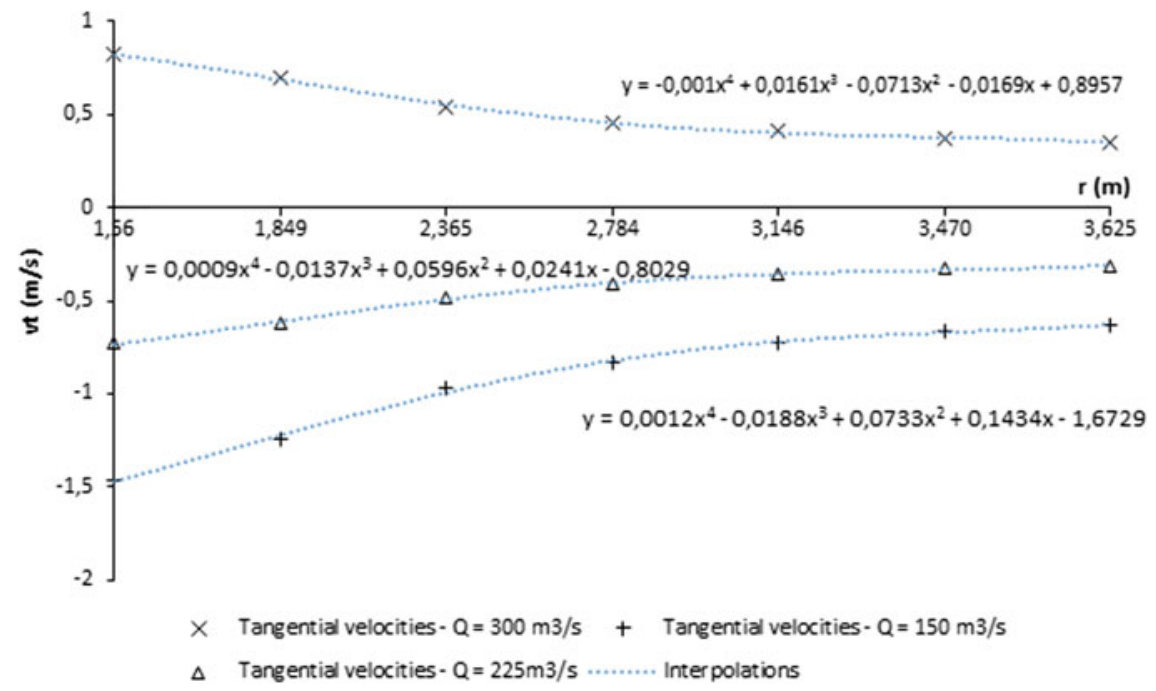

Fig. 4 Values of the tangential velocities (Vt) as a function of the distance to the turbines axis $(r)$ for three values of flowrate 
the simulations, with a slip boundary condition. The time step size was set to $0.06 \mathrm{~s}$, as it has proved to ensure numerical stability. The simulations were run for $20 \mathrm{~s}$ of physical time (20'000 iterations) and we checked that time convergence was achieved for this value. Each simulation lasted about $4 \mathrm{~h}$ and a half when launched on 56 Intel $^{\circledR}$ Xeon $^{\circledR}$ CPU E5-2697 v3 @ $2.60 \mathrm{GHz}$ (Haswell) processors.

\section{Results and Discussion}

\subsection{Description of the Turbine Exploitation Configurations}

The model validation is done through comparisons to field measurements and observations for several turbine exploitation configurations, which are summarized in Table 1. The groups are numbered from the left bank to the right bank. The case 1 consists of a symmetric repartition of flowrates, with a weaker flow close to the banks than in the center of the tailrace, so as to favour fish attraction. In case 2, the flow is concentrated on the right bank. In case 3, all the turbines pump the same flowrate. In case 4, one of the center groups (group 3) is stopped.

\subsection{Surface Flow Patterns}

Qualitative field observations of the flow patterns in the tailrace were done. The resurgences have been represented by circles (the diameters give an estimation of the resurgence sizes) and the direction of the flow is represented by arrows. The physical and numerical models results have been compared to these observations for each exploitation configuration (see Figs. 5, 6, 7 and 8). The first exploitation case consists of a symmetric repartition of the flow rate along the four groups. The flow rate is higher for the two central groups than for the two side groups (see Table 1). It is visible in the Fig. 5 that even though the turbining configuration is symmetric, there is a leftward deviation of the main flow in the tailrace. This deviation was observed in the field and is reproduced by the numerical simulations. However, in the numerical simulation, some recirculations appear close to the left bank that does not seem to have been observed in reality.

Table 1 Flowrate values of each group for the four turbining configurations

\begin{tabular}{l|l|l|l|l}
\hline & Group 1 $\left(\mathrm{m}^{3} / \mathrm{s}\right)$ & Group 2 $\left(\mathrm{m}^{3} / \mathrm{s}\right)$ & Group 3 $\left(\mathrm{m}^{3} / \mathrm{s}\right)$ & Group $4\left(\mathrm{~m}^{3} / \mathrm{s}\right)$ \\
\hline Case 1 & 100 & 250 & 250 & 100 \\
\hline Case 2 & 0 & 0 & 300 & 300 \\
\hline Case 3 & 215 & 215 & 215 & 215 \\
\hline Case 4 & 172 & 219 & 0 & 176 \\
\hline
\end{tabular}



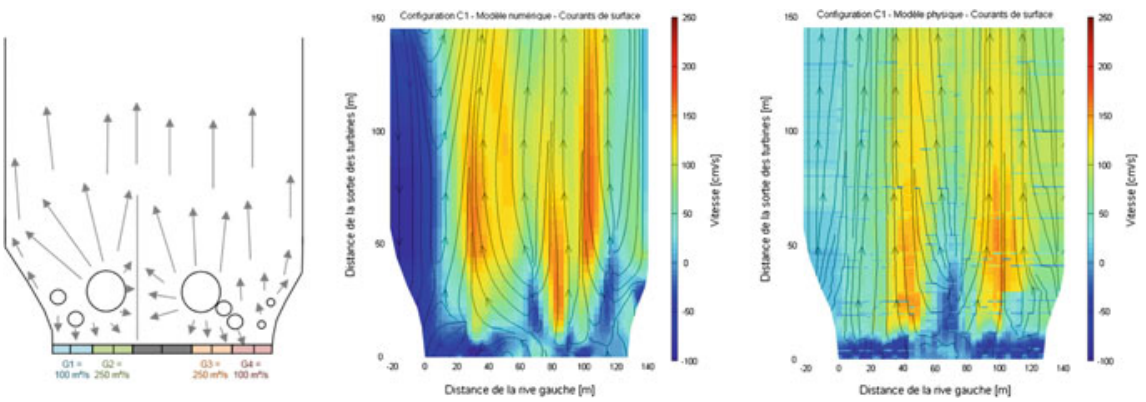

Fig. 5 Exploitation case 1-qualitative comparison of the observed surface flow patterns (left), the one from the numerical simulation (middle) and the one measured on the physical model (right). The colours correspond to the value of the longitudinal velocity, from $-100 \mathrm{~cm} / \mathrm{s}$ (blue) to $200 \mathrm{~cm} / \mathrm{s}(\mathrm{red})$
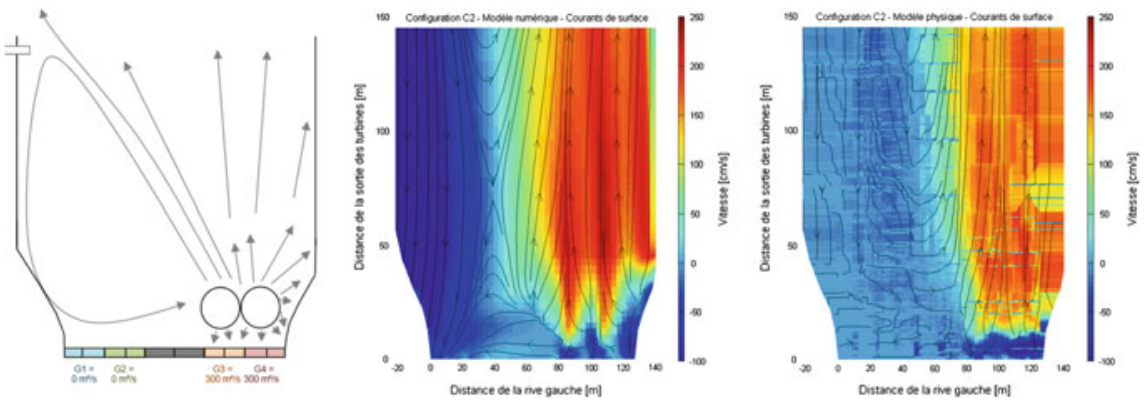

Fig. 6 Exploitation case 2-qualitative comparison of the observed surface flow patterns (left), the one from the numerical simulation (middle) and the one measured on the physical model (right). The colours correspond to the value of the longitudinal velocity, from $-100 \mathrm{~cm} / \mathrm{s}$ (blue) to $200 \mathrm{~cm} / \mathrm{s}(\mathrm{red})$
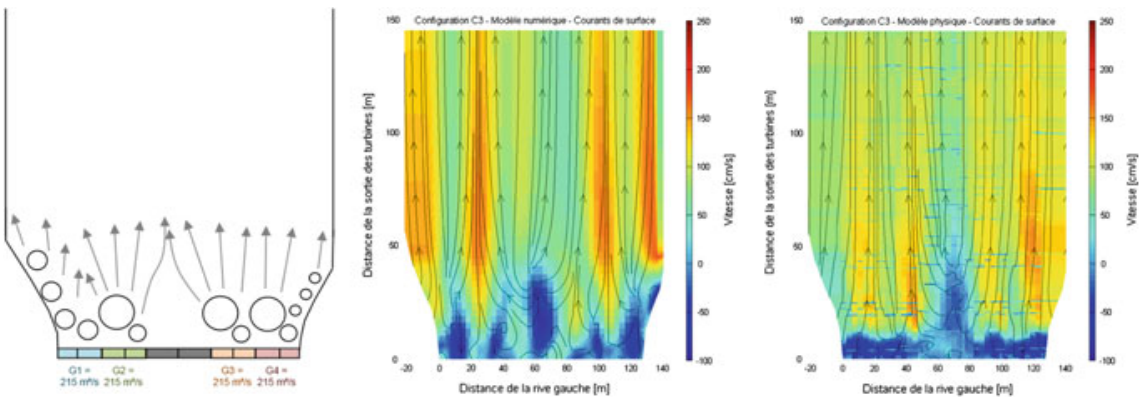

Fig. 7 Exploitation case 3-qualitative comparison of the observed surface flow patterns (left), the one from the numerical simulation (middle) and the one measured on the physical model (right). The colours correspond to the value of the longitudinal velocity, from $-100 \mathrm{~cm} / \mathrm{s}$ (blue) to $200 \mathrm{~cm} / \mathrm{s}$ (red) 

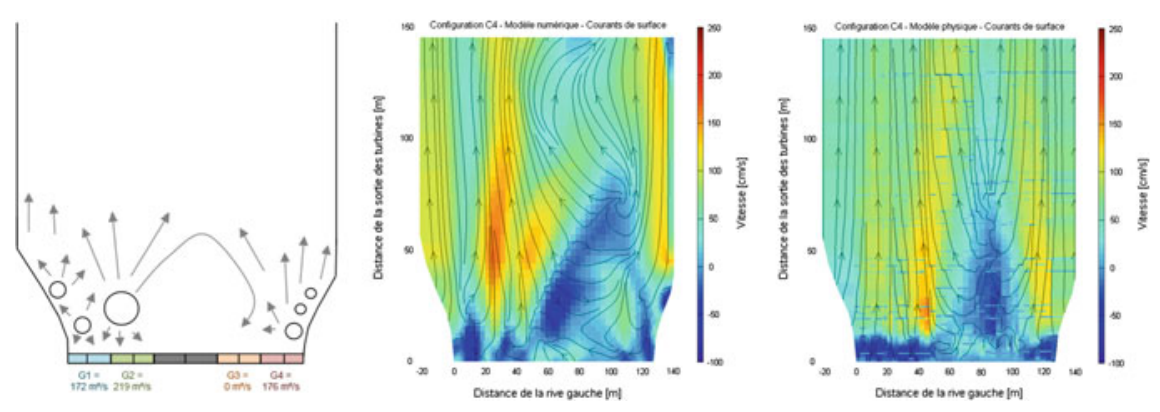

Fig. 8 Exploitation case 4-qualitative comparison of the observed surface flow patterns (left), the one from the numerical simulation (middle) and the one measured on the physical model (right). The colours correspond to the value of the longitudinal velocity, from $-100 \mathrm{~cm} / \mathrm{s}$ (blue) to $200 \mathrm{~cm} / \mathrm{s}$ (red)

The physical model reproduces fairly the main turbulence zones in front of groups 2 and 3 and the backwater effects at the turbines outlets (Fig. 5, right). One can also see the smaller velocities on the left bank, as observed on site and in the numerical results, but the leftward deviation is not really noticeable on the physical model. The recirculation on the left bank simulated by the numerical model is not to be found on the physical model, which better reproduces the observed flow in this case.

In the exploitation case 2, only the two right bank groups are active. Figure 6 (left) shows a large recirculation, well reproduced by the numerical simulation and by the physical model. The simulated velocities of this recirculation are strongly negative (between -50 and $-100 \mathrm{~cm} / \mathrm{s}$ ), while on the physical model they range between -50 and $0 \mathrm{~cm} / \mathrm{s}$. This zone seems also to be larger on the physical model than in reality; the recirculation has been observed approximatively on the first $150 \mathrm{~m}$ after the turbine outlets. On the physical model, it reaches the downstream end, corresponding to a distance of $280 \mathrm{~m}$. The positions of the resurgences are well represented by both models. However, one can observe a slight deviation of the turbulences toward the right bank on the physical model.

In the exploitation case 3, the flowrate is equal for all four groups. Figure 7 (left) shows that the flow is oriented in the longitudinal direction, which is well reproduced by the numerical model. The resurgence positions are also well reproduced by the simulation compared to the qualitative field observations. The same observations can be done on the physical model. However, the slight rightward deviation described for the case 2 is also visible in this configuration. The velocities on the physical model are lower and less concentrated than in the numerical model, where the outgoing jets are clearly visible up to $150 \mathrm{~m}$ after the turbines outlets.

The exploitation case 4 is the most complex one; the turbining scheme is dissymmetric, with one group stopped. Figure 8 shows that the resurgences positions are reasonably well reproduced by the numerical model, which also represents the recirculation between the groups 2 and 4 . However, the simulated recirculation 
seems longer than the observed one. Globally, the simulated flow better corresponds to the field observations on the left half of the channel than on the right side for this exploitation case. The physical model shows a good representation of the surface flow pattern, with a main resurgence in front of the group 2 . But as for the other cases, the resurgences are slightly deviated towards the right bank. The recirculation between the groups 2 and 4 is also visible, with a length that fits well the field observations; the streamlines become parallel at a distance of $150 \mathrm{~m}$ after the turbines outlets.

\subsection{Mean Velocity Field}

Acoustic Doppler Current Profiler (ADCP) measurements were done along the transverse section of the tailrace located right at the outlet of the afterbays. This chapter contains the comparison between the field measurements, the numerical and
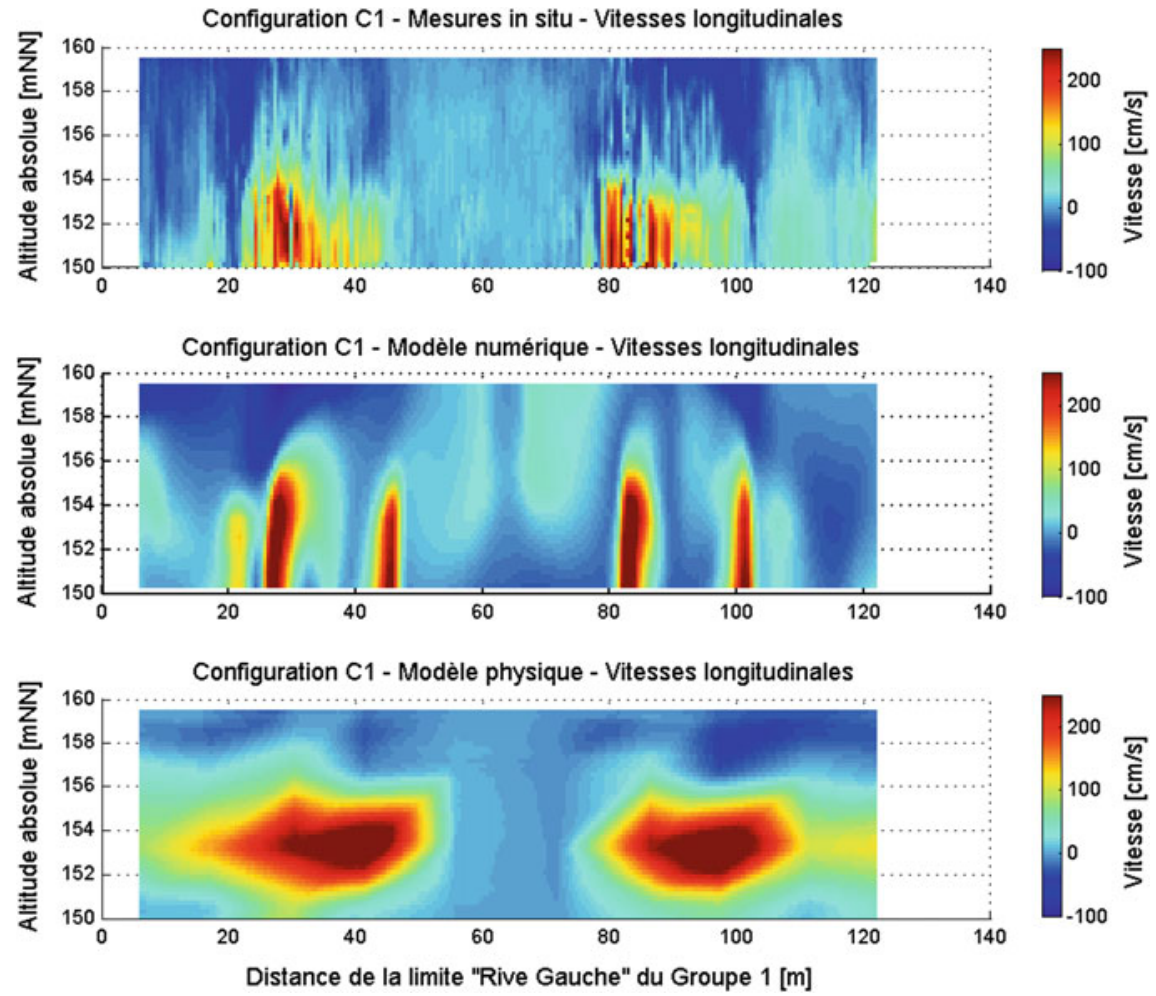

Fig. 9 Exploitation case $1-$ mean velocity field at $0 \mathrm{~m}$ from the exit of the afterbays. On-site measurements are on top, the numerical results in the middle and the physical model situations at the bottom. The colours represent the magnitude of the longitudinal velocity in $\mathrm{cm} / \mathrm{s}$ 
the physical models for the 4 exploitation configurations (see Table 1). For the turbining case 2 , the strong intensity of the flow hindered good field measurements. Therefore, the results are also compared to measurements located $50 \mathrm{~m}$ downstream of the afterbays outlet. Figures 9, 10, 11 and 12 show those results, with the longitudinal axis oriented towards the plots.

Figure 9 shows the results for the turbining case 1 . The jets transverse positions are well reproduced in the numerical simulation, especially on the left side. However, the simulated jets velocities are in average $30 \%$ higher than the measured ones. The physical model is also able to represent fairly the main patterns: the depth of the main flow (jets between 150 and $155 \mathrm{mNN}$ ) and the position of the jets at 20-40 and 80-100 m. The deviation towards the right bank of the jets observed during the surface flow analysis is clearly visible on those cross-profiles. The highest on-site measured velocities are located around 30 and $85 \mathrm{~m}$ of the left bank. Those same zones are visible at 35-40 and 90-95 $\mathrm{m}$ of the left bank on the physical model. Compared to the numerical model, one can observe a bigger dispersion of
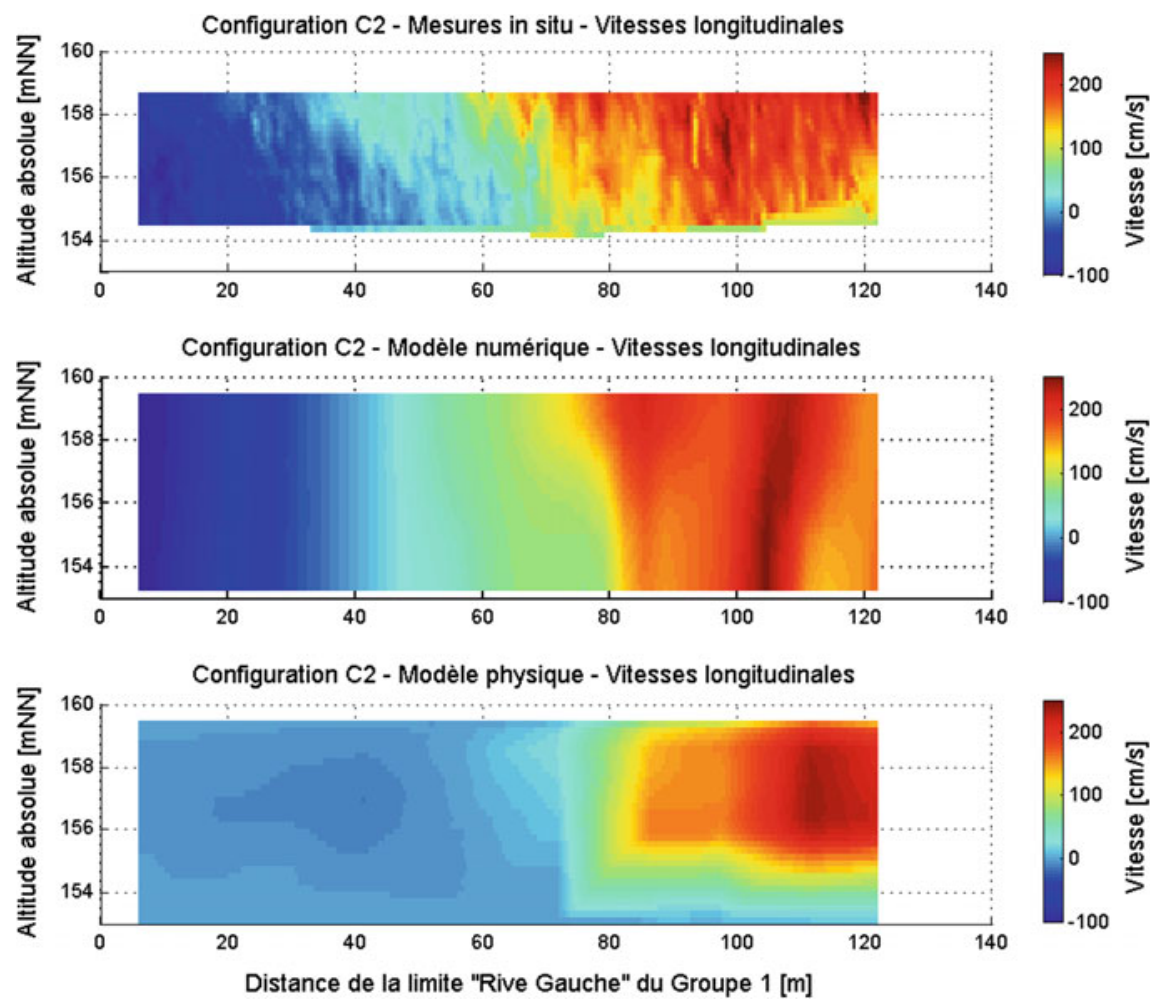

Fig. 10 Exploitation case 2-mean velocity field at $50 \mathrm{~m}$ from the exit of the afterbays. On-site measurements are on top, the numerical results in the middle and the physical model situation at the bottom. The colours represent the magnitude of the longitudinal velocity in $\mathrm{cm} / \mathrm{s}$ 

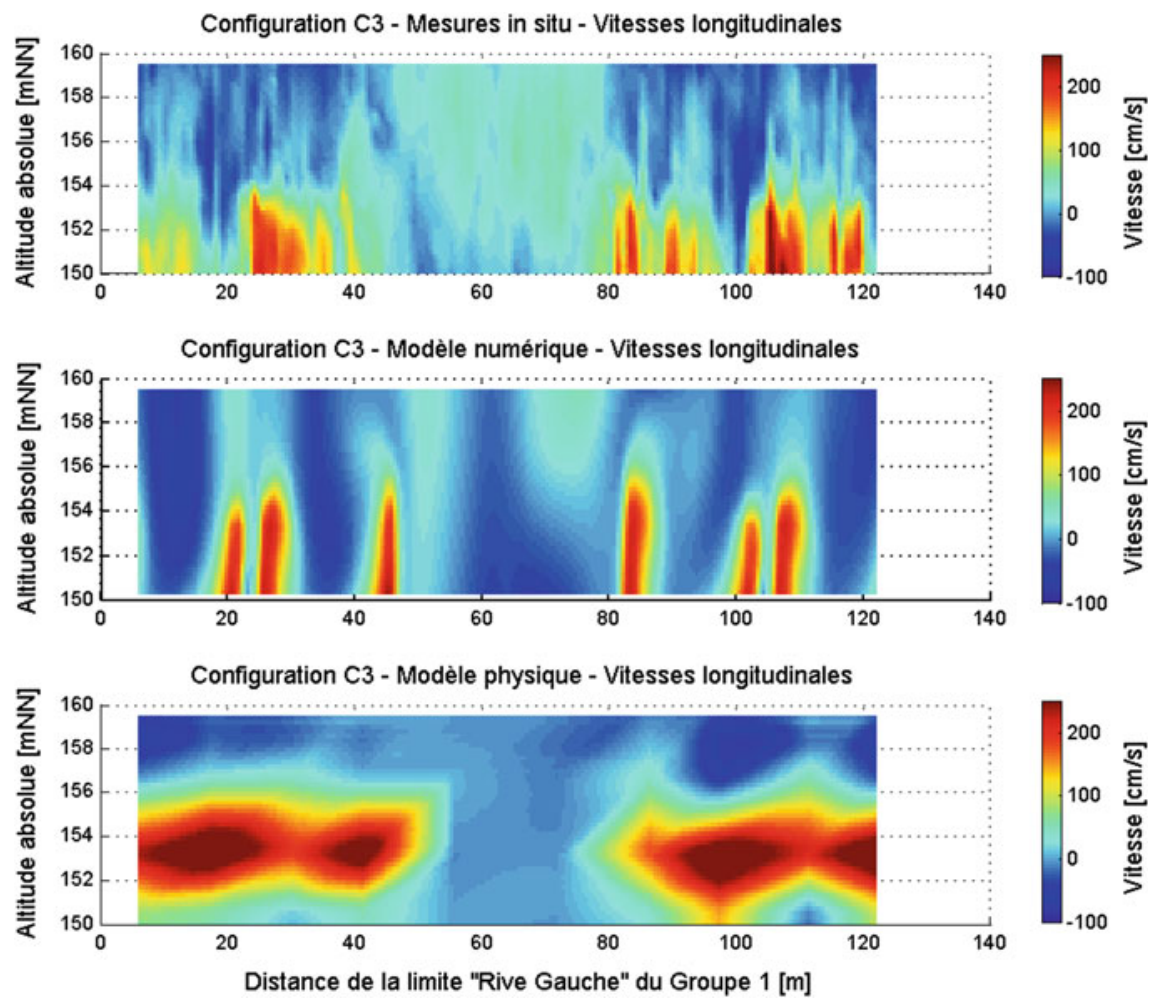

Fig. 11 Exploitation case 3-mean velocity field at $0 \mathrm{~m}$ from the exit of the afterbays. On-site measurements are on top, the numerical results in the middle and the physical model situation at the bottom. The colours represent the magnitude of the longitudinal velocity in $\mathrm{cm} / \mathrm{s}$

the jet on the physical model, where the jets of each turbine are well separated and $5 \mathrm{~m}$ wide. The velocities magnitude are in the same range.

For the turbining case 2, a lack of field data at the turbines outlet initiates the comparison $50 \mathrm{~m}$ downstream (Fig. 10). It is visible that the shape of the flow is quite well reproduced by the numerical simulation. The maximum value of the velocity on the right bank side is well predicted, while it is slight to high (towards negative $X$ ) on the left-bank side. The physical model shows good velocity magnitude in front of groups 3 and 4 and along the right bank. On the other side of the model, the recirculation shows velocities nearer to 0 than in reality. Compared to the field measurements and to the numerical model, the 5-10 m deviation toward the right bank is again observable.

Figure 11 presents the results for the exploitation case 3. The maximal jet velocities are correctly predicted by the numerical simulation, as are the heights of the jets. But those are slightly narrower than in reality. On the contrary, the physical model shows more diffused jets, having well-defined centers and positive velocities in the transition zones (between groups 1-2, and groups 3-4). Again, it can be seen 

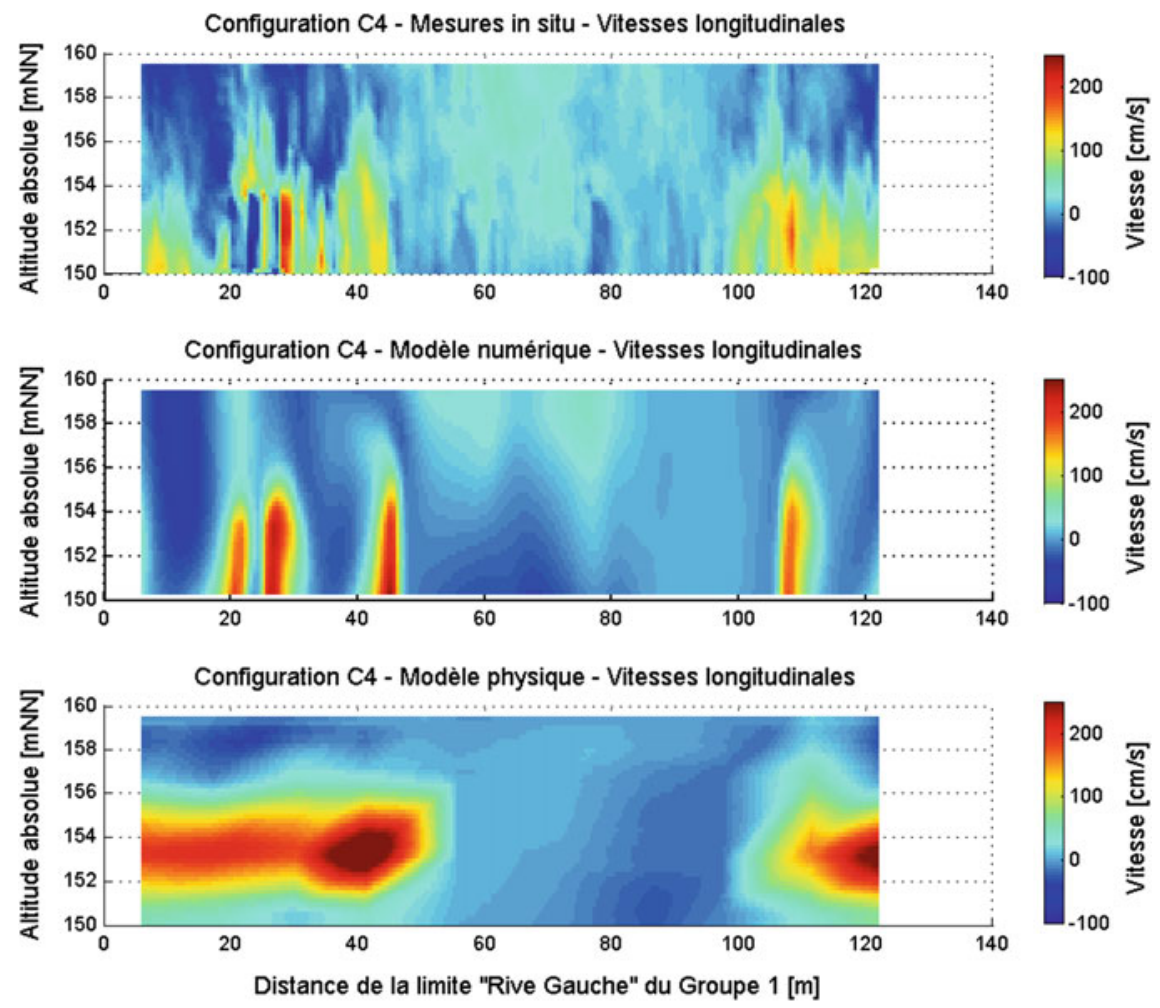

Fig. 12 Exploitation case 4-mean velocity field at $0 \mathrm{~m}$ from the exit of the afterbays. On-site measurements are on top, the numerical results in the middle and the physical model situation at the bottom. The colours represent the magnitude of the longitudinal velocity in $\mathrm{cm} / \mathrm{s}$

here that the centers (zone of highest velocity) of the jets are deviated towards the right bank. The magnitude of the jets, around $200 \mathrm{~cm} / \mathrm{s}$, corresponds to the velocities measured on the field.

For the exploitation case 4 (Fig. 12), the velocity magnitudes in the jet are well reproduced by the numerical simulation. The jet heights are also well predicted and their width is, as for case 3, slightly smaller than measured on the field. On the bottom of Fig. 12, the results of the physical model show the same particularity than for the other configurations, meaning a larger lateral dispersion of the jets and a deviation of the jets centers towards the right bank. The maximal velocities seem to be slightly higher than the ones measured on site. However, the quality of the field data for this profile is poor, as for the case 2. 


\section{Conclusion and Perspectives}

Concerning the numerical simulation, the presented results show that the model reproduces well the main flow patterns observed on site and that the simulated velocities, in particular, the highest et lowest values, fit the reality. The simulated jets are slightly more concentrated than in reality, even though a high value of turbulent intensity was prescribed at the inflows. Overall, the results are better for the exploitation cases 2 and 3, regarding both surface flow and cross-sections. These two configurations are the less complex ones regarding the distribution of the total discharge through the four turbines. Globally, the quality of the results shows that the numerical model is able to reproduce quite well the turbulent flow in the afterbays, and the main flow patterns in the tailrace.

On the other hand, the physical model shows a good representation of the flows occurring on site, both for surface and cross-profile flows. The turbulences and resurgences observed on site can also be observed in the model with precise longitudinal positions. In contrast, the lateral positions of the jets and main resurgences is systematically deviated from 5 to $10 \mathrm{~m}$ towards the right bank, independently of the group. Also, the lateral spreading of the jets is higher than in reality. As all groups have been built after the same construction drawings, this deviation is likely to be a consequence of the design, creating a preferential path in the right afterbay. But globally, the physical model recreates truthfully the flows in the afterbays and in the tailrace.

Acknowledgements This study is within the objectives of the Rhine Salmon 2020 rehabilitation project, followed by the members of the International Commission for the Protection of the Rhine. Patrick Durand from Ecotec, Geneva, Michel Larinier and François Travade are acknowledged for their expertise regarding fish pass inlet design and fish-friendly hydraulic conditions.

\section{References}

1. Klein, J., \& Oertel, M. (2015). Comparison between crossbar block ramp and vertical slot fish pass via numerical 3D simulation. In E-proceedings of the 36th IAHR World Congress, June 28-July 3, The Hague.

2. Ferrari, G. E., Politano, M., \& Weber, L. (2009). Numerical simulation of free surface flows on a fish bypass. Computers \& Fluids, 997-1002.

3. Heimerl, S., Hagmeyer, M., \& Echteler, C. (2008). Numerical flow simulation of pool-type fishways: New ways with well-known tools. Hydrobiologia, 609(1), 189-196.

4. Gisen, D. C., Weichert, R. B., \& Nestler, J. M. (2016). Optimizing attraction flow for upstream fish passage at a hydropower dam employing 3D detached-eddy simulation. Ecological Engineering. http://doi.org/10.1016/j.ecoleng.2016.10.065.

5. Pfister, M., \& Chanson, H. (2012). Scale effects in physical hydraulic engineering models. Discussion. Journal of Hydraulic Research, 50, 244-246.

6. M.-F. S. UVP-Duo Monitor User's Guide, 2014.

7. Viollet, P.-L., Chabard, J.-P., Esposito, P., \& Laurence, D. (2002). Mécanique des fluides appliquée. Paris: Presses de l'Ecole Nationale des Ponts et Chaussées.

8. EDF R\&D, Code_Saturne 4.1.1 Theory Guide. (2015). http://code-saturne.org/cms/ documentation. 